\title{
Research on the Promotion Path of College Students' Returning Home to Start Businesses under the Background of Rural Revitalization
}

\author{
Qiong Ou*, Youwei Chen, Min Peng \\ School of Economics and Management, Ji’an College, Ji’an City 343000, Jiangxi Province, China. E-mail: \\ 475291419@qq.com
}

\begin{abstract}
China has vigorously promoted rural revitalization in recent years. Under such background, there are more and more opportunities for college students to return home to start businesses, as well as for employment. Rural revitalization is mainly explored from three paths, namely local characteristic agricultural industry, rural tourism and rural Internet industry. To realize the success of college students' entrepreneurship back to hometown, it is necessary to improve their entrepreneurial awareness, strengthen the cultivation of their entrepreneurial ability, and set up a system about rural entrepreneurial knowledge. Through improving college students' entrepreneurial awareness and ability, it is conducive to efficiently collecting and integrating resources and improving their ability of controlling entrepreneurial risks. This article explores and analyzes the promotion path of college students' returning home to start businesses under the background of rural revitalization, aiming to enhance students' ability of starting businesses in their hometowns, and promote the revitalization of China's rural economy.
\end{abstract}

Keywords: Rural Revitalization; College Students’ Returning Home to Start Businesses; Promotion Path

In the context of rural revitalization, there are more and more rural college students returning home to start businesses, which provides a powerful driving force for the development of rural economy. In the development process of modern agriculture, agricultural and sideline products are becoming more and more popular, agritourism is beginning to spring up, and farm stay is even in short supply. However, the lack of high-quality talents is one of the most important factors restricting rural economic development. College students' returning home to start businesses will inevitably promote the development of rural economy. This article explores and analyzes the promotion path of college students' returning home to start businesses under the background of rural revitalization, aiming to enhance students' entrepreneurial ability and promote the revitalization of China's rural economy.

\section{Problems of college students' returning home to start businesses under the background of rural revitalization}

\subsection{Lack of initiative in returning home to start businesses}

China has vigorously developed the rural economy in recent years, and it is of great possibility that college students who return home to start businesses can achieved some success in the countryside. However, limited economic conditions and inconvenient transportation in rural areas, together with long distance from cities, great inconvenience in life, and difficult entrepreneurship environment, all discourage the enthusiasm of college students to return home for

This is an open-access article distributed under the terms of the Creative Commons Attribution Non-Commercial License (http://creativecommons.org/licenses/by-nc/4.0/), which permits unrestricted non-commercial use, distribution, and reproduction in any medium, provided the original work is properly cited. 
entrepreneurship. In addition, many parents think that only in the city can their children be promising, while they can only continue to endure hardships if they return to the rural areas. Therefore, they hope their children to have a stable job in the city instead of returning home to start businesses. Attitude of parents also greatly saps college students' enthusiasm for entrepreneurship. On the other hand, college students lack enough experience in starting businesses, as they have little entrepreneurial knowledge and rarely participate in related social practice activities during the college years. Moreover, because their life experiences are not rich enough, they may encounter obstacles when they communicate with local farmers and social workers. Besides, funds, interpersonal connections and social resources are required for rural entrepreneurship, which are very limited for college students, becoming another great obstacle for college students’ returning home to start businesses ${ }^{[1]}$.

\subsection{Lack of family economic and cultural support}

Entrepreneurship is a very severe challenge for newly graduated college students, in which process there is full of instabilities. It requires super self-confidence of college students and family support. No matter in economy, culture or spirit, support from the family is the powerful internal strength in entrepreneurship ${ }^{[2]}$.

\subsection{Imperfect system of university entrepreneurial innovation teaching}

College students mostly contact with teachers and classmates, and seldom with the outside society. Even in the internship stage, they have little social practice experience, which is directly related to the imperfect educational system of entrepreneurship in colleges and universities. Specifically, there are few practical courses in entrepreneurship and innovation, and students have few opportunities to contact the society, especially the rural society. College students' returning home to start businesses has been hindered.

\subsection{Ineffective implementation of the national policy on entrepreneurship}

Different from employment, entrepreneurship requires students to possess various skills, and also calls for national policy support. Although China has introduced relevant policies and played a role in innovation and entrepreneurship, as well as providing great support, the effect of specific implementation is far from ideal, and many policies are inconsistent with the real society. In addition, the complexity of starting businesses and the variability of the market further enhance the difficulty of college students' entrepreneurship, resulting in poor entrepreneurial effect ${ }^{[3]}$.

\section{Factors affecting college students' returning home to start businesses under the background of rural revitalization}

\subsection{Personal factors of college students}

To overcome the obstacles of starting businesses in their hometown, college students need to have relevant ability. The result of entrepreneurship varies with comprehensive factors, and the hardships are not bearable by every student. The support of college students' ability and from families will make their entrepreneurial success rate higher, and on the contrary, entrepreneurship will become more difficult.

\subsection{Family factors of college students}

China's rural economy has developed rapidly and made remarkable achievements in recent years. However, many rural parents haven't updated their ideas timely. They keep the idea that their children will suffer hardships if they return to the countryside after graduation, and hope them to get decent jobs in cities. On the other hand, starting businesses is full of unknown factors, which requires students to have a lot of courage and sufficient basic knowledge and skills as the support. Meanwhile, funds are needed for starting businesses, which makes it difficult for many students from poor families to stick to it.

\subsection{Influence of higher education}

College students' returning home to start businesses is greatly influenced by higher education. The state encour- 
ages college students' entrepreneurship and creates a very favorable entrepreneurial atmosphere. Moreover, colleges and universities have carried out entrepreneurship education and organized entrepreneurial competitions for college students. There is a certain entrepreneurial mechanism. However, there are still some problems in the specific implementation, such as the lack of entrepreneurial instructors. Colleges and universities have failed in setting up a tutor team, and students are not given targeted and professional guidance. Besides, the lack of innovation in the content of entrepreneurship education and the lack of matching teaching materials are also important factors that affect college students returning home to start businesses ${ }^{[4]}$.

\subsection{Influence of the society}

Entrepreneurship is quite difficult, requiring knowledge, skills and constant inner motivation. With the increasing number of college graduates in recent years, the state vigorously advocates college students' entrepreneurship, and provides abundant resources, creating a favorable entrepreneurial atmosphere and providing great convenience for college students. However, entrepreneurship is extremely complex and involves various aspects. It requires students to have full enthusiasm and be able to fully understand and analyze the social factors such as successful entrepreneurial cases and entrepreneurial opportunities, so that they can be confident and devote themselves to the entrepreneurial process.

\section{The promotion path of college students' returning home to start busi- nesses under the background of rural revitalization}

\subsection{Strengthen the cultivation of college students' entrepreneurial ability}

College students should be taken as the main body of entrepreneurship, whose comprehensive quality will directly affect the success of entrepreneurship ${ }^{[5]}$. Therefore, college students must absorb the relevant entrepreneurial knowledge learned at school to enhance their entrepreneurial ability. Meanwhile, they need to build entrepreneurial teams and expand their interpersonal connections and resources. Moreover, college students also take an active part in the entrepreneurship competitions during their school years, and actively participate in entrepreneurial practice activities, so as to promote their entrepreneurial ability. Last but not the least, there are many obstacles in the process of rural entrepreneurship, and entrepreneurial projects may stagnate, which calls for high psychological quality and risk resistance of entrepreneurs. Therefore, only by strengthening the quality construction of college students and improving their ability to resist pressure and risks, can they do better in entrepreneurship.

\subsection{Strengthen college students' entrepreneurial awareness from the perspective of family}

The formation of college students' entrepreneurial consciousness is easily influenced by various factors, which can be divided into external and internal factors. The former consists of family factors, educational factors and social factors, while the latter refers to the entrepreneur's individual characteristics, economic status, entrepreneurial ability and so on. These internal and external factors are intertwined and inseparable. Therefore, it is necessary to closely combine entrepreneurship with school education and students' entrepreneurial awareness. In terms of school education, a perfect education system should be built for college students' entrepreneurship, including designing courses for entrepreneurship education. For junior college students, courses related to entrepreneurship should be designed to create an entrepreneurial atmosphere, help students form a perceptual cognition of entrepreneurship and arouse their entrepreneurial interest. As for the senior students, colleges and universities should offer elective courses related to entrepreneurship and management to them, and cultivate students' entrepreneurial recognition ability according to their aptitude and different majors. Meanwhile, students should constantly strengthen the construction and cultivation of their own quality in their daily study and life, as well as participate in entrepreneurial experience sharing activities. Moreover, students should actively learn the relevant preferential policies of the state. By cultivating their entrepreneurial awareness, college students will be more willing to participate in rural entrepreneurship, and constantly improve their self-confidence in innovation in the process of starting businesses.

\subsection{Strengthen innovation and entrepreneurship education of colleges and universities}


College students' entrepreneurial ability is directly related to innovation and entrepreneurship education. Therefore, colleges and universities should organize as many innovation-related activities as possible, such as entrepreneurship online courses, selection of entrepreneurship star, and innovation cases sharing. They should also build a perfect innovation knowledge system and create a favorable entrepreneurial climate and environment on campus. Students need to experience the hardships of starting businesses in the study of entrepreneurial knowledge and the participation of entrepreneurial practice activities; thus, they can have a proper entrepreneurial mentality. At the same time, colleges and universities should also enrich the practice activities and connect with business projects by settling in the business incubator and business base of college students. Nevertheless, through the construction of curriculum system, educational practice system, cultural system and tutor guidance system in entrepreneurship education in colleges and universities, a more scientific, characteristic and systematic entrepreneurship education model can be established.

\subsection{Introduce innovative preferential policies}

To encourage college students to start businesses and obtain employment, the policy on innovation and entrepreneurship has been gradually introduced in recent years, which has obtained great attention from society ${ }^{[6]}$. Entrepreneurship in various fields, represented by Internet technology, has played a very important role in people's production and life, and has changed people’s lifestyle. However, most of these entrepreneurs from middle and upper levels who occupy various resources. On the contrary, although the newly graduated college students have solid professional knowledge, they have less entrepreneurial experience and are not familiar with many fields. In comparison, there is more possibility for rural college students to return home to start businesses, especially in the context of rural revitalization, making rural entrepreneurship a hot choice. At the social level, the state must innovate the entrepreneurial environment, introduce relevant innovative preferential policies and regulations in consistent with the local characteristics, and create a favorable entrepreneurial environment. In addition, the state should also achieve smooth connection and communication with universities, and set up rural innovation and entrepreneurship incubation bases, to encourage more college students to voluntarily participate in rural entrepreneurship and offer suggestions for rural economic revitalization.

\section{References}

1. Lu Y. The constraints and path selection of college students' returning home for entrepreneurship and employment under the background of rural revitalization (in Chinese). Agricultural Economy 2020; (8): 104-105.

2. Liu J, Zhen F. Research on the influencing factors and countermeasures of female college students' returning home to start businesses in the perspective of rural revitalization. PR World 2020; (14): 40-41.

3. Wang S, Guo X, Chen S. Research on the opportunity of college students' returning home to start businesses under the background of rural revitalization (in Chinese). Modern Agricultural Research 2020; (5): 9-10.

4. Zhan T. Research on the problem of college students' returning home to start businesses under the background of rural revitalization (in Chinese). Journal of Puer University 2020; 36(2): 86-88.

5. Zhang Y, Wu Z. Investigation and countermeasures of college students' returning home to start businesses under the background of rural revitalization strategy - Taking northern Jiangsu as an example (in Chinese). Journal of Jilin Agricultural Science and Technology College 2020; 29(2): 17-21.

6. Wang L. Rural revitalization leads rural college students to return to hometown to start businesses in the new era (in Chinese). Shangqing 2020; (4): 113. 